\title{
Visualidade háptica no cinema de museu
}

\author{
Ruy Cézar Campos Figueiredo ${ }^{1}$ \\ DOI 10.20396/eha.vil4.3352
}

Distingue-se, na História da Arte, visualidade háptica de visualidade óptica. A última toma e proporciona um distanciamento suficiente para que as coisas sejam percebidas como formas distintas no espaço, dependendo da separação entre o sujeito espectador e o objeto. A visualidade háptica, distintamente, tende a se mover sobre a superfície do seu objeto ao invés de criar uma profundidade ilusionista, não para distinguir formas, mas para explorar texturas.

O austríaco Alois Riegl é quem primeiro tomou emprestado o termo háptico dos estudos de fisiologia e o empregou no campo da História da Arte para realizar a distinção entre a visualidade háptica e a visualidade óptica, sendo a última marcada, sobretudo, pelo distanciamento entre sujeito e objeto. Marks nos aponta como depois de Riegl, Adolf Hildebrand e outros historiadores da arte foram os primeiros a observarem as variações culturais da representação do espaço em imagens e as analisar desde uma abordagem histórica sobre o olhar.

É com teóricas feministas dos estudos fílmicos como Laura Marks que uma contraposição crítica a abordagem de Riegl ganha repercussão na contemporaneidade. $\mathrm{O}$ austríaco observou o desenvolvimento do estilo háptico da antiga arte egípcia, que mantinha a aparência isolada dos objetos, em unificação e aderência ao plano, em direção ao estilo óptico da arte romana tardia e a influência dos bárbaros em um tipo de relação com a imagem pautada na transcendência, onde falta uma conexão tátil entre os objetos e o plano. Para Marks², ele explicitamente aponta que a arte ocidental, de maneira evoluída, buscou a similaridade com os objetos através da representação, em vez de através do contato, no que se colocou, para o historiador, uma crescente abstração e participação do simbólico. É com ironia que Marks se contapõe a essa leitura:

$O$ atual engajamento intelectual com a questão da corporificação e o interesse crescente entre os artistas por obras sensuais e hápticas repudiam a teleologia de Riegl da subjetividade singular e descorporificada (ou, se se quiser interpretar Riegl mais generosamente, elas demonstram uma mudança em sua proposta dialética). Essas mudanças recentes refletem a reavaliação das tradições não Ocidentais e Ocidentais 'menores' de arte material

\footnotetext{
1 Artista-pesquisador. Doutorando em Tecnologias da Comunicação e Cultura na Universidade do Estado do Rio de Janeiro. Mestre em Artes e Processos de Criação: Poéticas Contemporâneas na Universidade Federal do Ceará.

2 2004, p. 168
} 
e sensual que Riegl via como inferiores ${ }^{3}$

Na década de 1990, é no campo de experimentação com a imagem em movimento que o espaço do museu é invadido por uma diversidade de imagens hápticas singulares em sua presença, que evocam toda uma diversidade de leituras a partir das questões envolvendo a experiência corporificada da imagem em movimento no espaço do museu. A partir dessa década, autores como Dubois, Elsaesser e Uroskie crêem se dar os fenômenos mais interessantes da imagem em movimento na contemporaneidade. Aqui, acredita-se que uma das características dessa presença é a visualidade háptica. Pensar as relações táteis na experiência da audiovisualidade cinematográfica marca um movimento de não se pensar o filme como um exterior distanciado para o pensar como um contato somático direto. Não se trata, de acordo com Elsaesser ${ }^{4}$, de complementar o visual com o háptico dos sentidos para uma Gesamtkunstwerk, um trabalho total de arte, mas de ensejar uma configuração alternativa de agendas para a imagem em movimento, a percepção e a experiência perceptiva.

Nessa abordagem, a comunicação acontece a partir do contato corporal entre o filme e o espectador, através da experiência corporificada em estruturas que são compartilhadas audiovisualmente, uma situação na qual a consciência da corporificação de si é a condição radicalmente irredutível de empatia com o Outro ou com uma situação que não é a sua 5 . Difere, nesse sentido, das abordagens teóricas sobre o cinema que Elsaesser chama de "neoformalistas", que buscam por pistas para sugerir um certo alinhamento cognitivo ou emocional da personagem no filme com o espectador de cinema.

A visualidade háptica ou tátil se delineia, de acordo com Marks (2004, p. 160), reduzindo os fossos que separam o que é percebido de quem percebe, aproximando do corpo as sensações e a experiência, posicionando os olhos como órgãos do toque, pensando o tocar como um sentido localizado na superfície do corpo, forçando o visualizador a contemplar a imagem em si mesmo em vez de apenas ser empurrado para uma narrativa. O olho háptico não existe em exclusão da olho óptico, o que fica claro através de situações práticas: é difícil olhar de perto a pele de um amante com uma visão óptica; é difícil conduzir um carro com uma visão háptica. ${ }^{6}$

O foco se coloca em texturas, close-ups em corpos, expressões táteis como arrepios e objetos

\footnotetext{
3 MARKS, 2004, p. 168; trad. livre

42015, p. 140

5 2015, p. 129

6 .2004, p. 163; trad. livre
} 
que podem trazer, em sua materialidade, memórias que possam estar virtualmente presentes para o espectador. Essas memórias são atualizadas através do filme ensejando uma compreensão da memória como processos que envolvem o aparato perceptivo por inteiro e não só processos mentais.

Os anos 1990 se estabeleceram na memória bastante relacionados ao contexto da globalização, do capitalismo global com a formação de blocos econômicos, da crescente popularização de tecnologias de comunicação em rede, do uso mercadológico do conceito de aldeia global ao mesmo tempo que de novas ondas diaspóricas prófugas da pobreza e de guerras. As concepções de lugar e espaço foram profundamente afetadas por esse contexto e o cinema no espaço do museu proporcionou o contato com imagens táteis profundamente vinculadas com essa renovação conceitual.

Conforme $\mathrm{Weibel}^{7}$, é o desenvolvimento de novas abordagens narrativas para a imagem em movimento que mobiliza os artistas que passam a expor em galerias e museus o cinema enquanto arte. Artistas como Doug Aitken, Isaac Julien, Pipilotti Rist, Tacita Dean, Douglas Gordon compõem o que seria uma geração que se interessa nas múltiplas projeções e ecrãs a partir da vontade de pensar uma narrativa com múltiplas perspectivas, desconstruindo o dispositivo cinematográfico no dispositivo museológico. Não mais interessados em uma psicologia de causa e efeito para a narrativa cinematográfica, suspende-se a linearidade, transformasse o giro (loop) em recurso, e se utiliza da multiplicação de telas para experimentar a não sincronia espacial e temporal de planos, com trajetórias de narração sendo estabelecidas a partir de uma força centrífuga de múltiplas perspectivas. Essas são as características do que Weibel chama de "reversibilidade rizomática"8 marcante dessa produção.

Verheul ${ }^{9}$ nos aponta como alguns desses trabalhos, ao se utilizarem de múltiplas projeções, estabelecem sua poética não só pelas qualidades narrativas, nem tampouco apenas por suas questões formais, mas por uma combinação de tais através das qualidades de mise-en-scéne, cinematografia, montagem, multiplicidade de projeções, edição espacial (a interação entre as múltiplas projeções) e a instalação espacial das projeções. Ela argumenta, por exemplo, que as instalações com múltiplos ecrãs, através de suas características espaciais, ensejam um senso de desorientação tanto nos espectadores quanto na experiência dos protagonistas dos filmes instalativos.

A edição espacial, que ocorre por vezes através da conexão e disjunção espacial entre as pro- 
jeções, produz uma forma de expectação marcada pela navegação, na qual o espectador deve explorar e entrar em contato físico com as imagens que o envolvem em expressões desorientadoras de tempo e espaço, por vezes relacionadas a desorientação espacial e temporal causada pelo contexto de globalização que se deu intensamente a partir de 1990. Espectador e protagonistas experienciam instabilidades na fronteira entre casa e mundo e entre eu e mundo por meio de locações "entre-meio", que expressam cinematograficamente o encontro intercultural, especialmente a experiência de deslocamento como um senso tátil de desorientação.

Através da multiplicação de imagens no espaço, múltiplas camadas de tempo são apresentadas simultaneamente, levando a uma confusão da cronologia e da linearidade. Por meio das qualidades táteis, experiências desorientadoras de viagem das protagonistas e de deslocamento são expressas diretamente para o espectador corporificado.

Através de teorias relacionadas a questão de lugar, espaço e deslocamento, creio que os artistas-pesquisadores na área podem levantar um conhecimento diverso sobre as relações entre as narrativas contemporâneas e a própria dinâmica global da contemporaneidade, onde através de uma materialidade encontrada em um ponto específico e que afeta uma comunidade isolada, como no meu caso do carvão, encontram-se relações globais e toda uma lógica de capitalismo global e desenvolvimento traumático.

Ao se pensar na produção e análise dessas imagens desde uma ênfase fenomenológica e háptica, abre-se a possibilidade de se articular a imagem em um nível da experiência somática. Conforme a imagem em movimento circula sem tantas restrições no espaço do museu e da galeria, as possibilidades de criação com ela podem se espalhar nas experiências que envolveram performance e cinema expandido, um campo ainda pouco explorado por pesquisadores e cuja diversidade de experiências já existentes ainda foram pouco exploradas tanto no campo das artes como da academia.

Enquanto artista, tenho me mobilizado em torno das relações entre cine-instalação em múltiplos canais com visualidade háptica e teorias de lugar, espaço e deslocamento. Essa é, portanto, uma pesquisa em desenvolvimento desde uma perspectiva pessoal de artista-pesquisador, o que justifica em termos conclusivos a adoção de uma primeira pessoa, reverberando a discussão acima da importância de que o conhecimento sobre espaço seja situado também a partir da experiência espacial de quem pesquisa ou faz arte.

O conhecimento gerado, em um nível individual, tem repercutido diretamente no meu próprio processo de criação enquanto artista. Penso diretamente nos efeitos de tal estudo na minha 
própria poética e experiência enquanto artista. Passei a lidar com essas questões a partir do processo de criação da cine-instalação-performance Carvão Para Seus Olhos Tocarem, que se desdobra em ações e múltiplas projeções audiovisuais relacionadas ao meu engajamento em uma dinâmica de materialidades, sensorialidades, pessoas e lugares caracterizados por uma multiplicidade de eventos de deslocamento, com um interesse e direcionamento específico à materialidade do carvão mineral com a qual passei a me relacionar conforme fui me envolvendo com a presença de tal matéria no Pecém, anteriormente um distrito de pescadores e casas de veraneio à $50 \mathrm{~km}$ de Fortaleza, no Ceará, e atualmente um complexo industrial, palco importante da política de desenvolvimento econômico do estado no começo do século XXI. O carvão mineral do Pecém me colocou em contato com a paisagem do lugar, com pessoas que vivem na região e que compartilharam comoventes dramas, narrativas de deslocamento, reassentamento e de poluição ambiental para o projeto, consistindo a performance cine-instalativa em um modo de compartilhamento desse contato. Também me levou ao estado de La Guajira, na Colômbia, onde o carvão que chega ao Pecém é extraído, afetando e deslocando as comunidades da etnia Wayuu, dentre outras.

Testemunho, enquanto artista-pesquisador, que através do uso das múltiplas projeções, configura-se um espectro de possibilidades revigorantes da experiência da imagem em movimento no campo epistemológico de produção artística. As imagens envolvem o espaço dos museus e da galeria com suas narrativas que trazem um senso de desorientação espacial e intensidade demandando um tipo de engajamento da atenção voltado para a multiplicidade, onde o diretor não tem como intenção direcionar e controlar o olhar e o corpo do espectador em relação com a tela, mas promover um contato corporal e somático em que o espectador se depara com uma versatilidade de opções para a experiência.

Através de teorias relacionadas a questão de lugar, espaço e deslocamento, creio que os artistas e pesquisadores na área podem levantar um conhecimento diverso sobre as relações entre as narrativas contemporâneas e a própria dinâmica global da contemporaneidade, onde através de uma materialidade encontrada em um ponto específico e que afeta uma comunidade isolada, como no meu caso do carvão, encontram-se relações globais e toda uma lógica de capitalismo global e desenvolvimento traumático.

Ao se pensar na produção e análise dessas imagens desde uma ênfase fenomenológica e háptica, abre-se a possibilidade de se articular a imagem em um nível da experiência somática. Conforme a imagem em movimento circula sem tantas restrições no espaço do museu e da galeria, as possibilidades de criação com ela podem se espalhar nas experiências que envolveram perfor- 
mance e cinema expandido, um campo ainda pouco explorado por pesquisadores e cuja diversidade de experiências já existentes ainda foram pouco exploradas tanto no campo das artes como da academia.

\section{Referências Bibliográficas}

BRUNO, Giuliana. Surface: matters of aesthetics, materiality and media. Chicago: University of Chicago Press. 2014.

CHUBB, E.. Small Boats, Slave Ship; or, Isaac Julien and The Beauty of Implied Catastrophe. Art Journal Open. 2016. Disponível em: [http://artjournal.collegeart.org/?p=7197]. Acessado em 03 de julho de 2017.

CONNOLLY, Meave. The Place of Artists Cinema: Space, Site and Screen. Chicago: University of Chicago Press. 2009.

DUBOIS, Philipe. "Um "efeito cinema" na arte contemporânea". in: Dispositivos de registro na arte contemporânea. Org. Luiz Cláudio da Costa. Rio de Janeiro: Contra Capa Livraria / FAPERJ. 2009.

MARKS, Laura U. The Skin of the Film: Intercultural Cinema, Embodiment, and the Senses. Durham and London: Duke University Press, 2000

MASSEY, Doreen. For Space. Londres: Sage. 2005.

NAFICY, Hafid. An Accented Cinema: Exilic and Diasporic Filmmaking. Princeton: Princeton University Press. 2001

STEMMRICH, G.. White Cube, Black Box and Crey Areas: Venues and values. Gregor Stemmrich. in: Art and The Moving Image. A critical Reader. Ed. Tanya Leighton. Tate Publishing. Pp430-445. 2008.

UROSKIE, Andrew. Between the Black Box and the White Cube: Expanded Cinema and Postwar Art. Chicago and London: University of Chicago Press. 2014

VERHEUL, T.. Between Screens, Between Identities. Multi-Screen Installations and Interculturality. 2011. Master Media Studies. Amsterdam, University of Amsterdam. 2011

WEIBEL, Peter. Narrated Theory: Multiple Projection and Multiple Narration. In: New Screen Media. Cinema/Art/Narrative. Andrea Zapp and Martin Rieser (eds). SFI Publishing. London, 2002 